on the faintest hints of nature, and with more or less consciousness of insight into law is able to control the process.

The modern theory of musical quality, or timbre, for which we are indebted primarily to Johannes Muiller, and subsequently to Helmholtz, who by elaborate investigation has made the subject specially his own, takes account only of the varying intensities of the harmonics present in the compound tone, classed in two series, the "open" and the "stopped," or otherwise the "even" and "uneven," in regular progression. To the system of asso. ciated sounds in harmony the present inquiry has no reference ; my purpose is to press the claim for recognition of another series in addition to these, to show that quality, and especially mimaphonic quality, in sounds, in whatever degree attributable to harmonics combined with the fundamental, is no less dependent for its character on the "order" in which harmonics come on or develop themselves in the growth of the tone. In plants there is a direct order of appearance-leaves, then flowers; a reversed order is as natural, and flowers come before leaves.

If an "open diapason" pipe of small scale is taken, and some slight variation made in the voicing, the pipe may be converted into a "flute harmonique," and it will give a note an octave higher than before ; that is to say, the fundamental is abolished, and the octave or first harmonic reigns in its stead. The pipe will probably be now "unsteady," frequently attempting to reinstate the fundamental. This tendency we may counteract by drilling a small pin-hole at the side of the pipe, and the triffing amount of external air thereby admitted will destroy the tendency, by preventing the perfect formation of the node required by the fundamental. The perforation should be made at the true point of localisation of the node, which (as explained in a former letter in NATURE, vol. ix., p. 301 ) is at about $\frac{3}{7}$ of the whole length of pipe reckoned from the level of the mouth. If we next enlarge the hole at the foot of the pipe, thus allowing greater force to the wind-current, and if we have properly manipulated the pipe, we shall on the trial of its sound hear the twelfth coming on as the forerunner of the octave, most distinctly and with a perceptible interval between the appearance of the twelfth and octave. The effect is more certain if the mouth is cut to a height less than that marked by scale, which would be $\frac{1}{3}$ of the width of mouth; and if, further, the pipe is slightly coned-a provision favouring the harmonic. By other changes of treatment, the fifteenth or double octave may be brought out as the intro. ductory harmonic, and the twelfth following, and if we will we may restore the original ground-tone. The "flute harmonique" in this style is to be chosen for this experiment, not as representative of quality, but that in this overstrained condition it clearly defines the entrance of each harmonic, the order of succession, and the interval between each. In other varieties of pipe the "quality" is characterised by these harmonics, and in this order, but so blended as it were in a "portamento" glide that even critical ears fail to detect the elements combined into the effect. It is, so to speak, "an excess "of nature, which is olten necessary to open our eyes to the perception of her commonest realities.

A diapason pipe is never so strong and brilliant in character as when it is just verging on the transmutation of fundamental to octave; for good vigorous quality, therefore, it is restrained only to just within the limit; nevertheless the presence of the octaveharmonic as the precursor of the fundamental should always be felt with its jubilant energy, then afterwards, the fundamental taking full possession of the pipe, producing its own octaveharmonic with almust equal exuberance of power. The precursory harmonic is of the transitive order. We have to recognise two distinct series of open harmonics-the direct order, over-tones of the pipe, which are derivatives of the fundamental, and the inverse order, the tones of which may be called stem-tones of the reed, for they are thrown off by the reed in swift succession, and declare the non-isochronous nature of the airreed's motion. There is nothing erratic about these stemnal harmonics or the order of their appearance ; they are due to the untamed vigour of the reed, and have this distinguishing lawthey are transitive, each one dies in giving birth to the next, whereas the over-tones of the pipe coexist with the fundamental, and are the direct consequence of the excess of excitation in the air-column of the pipe (see more at length in NATURE, vol. viii., p. 383), providing a safety-valve for the permanence of pitch in the ground-tone, by employing the surplus energy acquired from the reed's vivacity in new forms of growth.

Whenever from an organ-pipe we hear harmonics together with the fundamental, then the air-reed is vibrating to its fullest mplitude, for it is the superabundant vitality of the air-colimn that sustains the coexistent ones; but when we hear harmonics independent of the fundamental, then we may be sure that they are the expression of the higher activity of the reed itself, then working with lessened amplitude of motion, yet with greater velocity of vibration.

The genesis of these tones is due to the association of reed and pipe. Without the pipe the reed could not produce tone, would be barren as one sex. As the pipe is silent and requires some external impulses to bring it into life, so the air-reed needs something to act upon before it can vibrate or swerve from its course in minute degree ; some inequality of environment is all it asks some alliance with power distinct from its own. Take away the pipe, leave it only the mouth, and it will pull against that and begin to work according to its nature, and even in that rudimentary condition will elicit tone of definite pitch.

Many classes of organ-pipes give harmonics of the direct order without a trace of those of the inverse order; on the other hand, the several varietles of pipes which give the inverse order invariably yield the direct order subsequently with the ground tone; and why? It will be comprehended at once, if I have rendered my meaning clearly, that the initial harmonics proclaim the intense vigour of the reed, and that force, unabated in strength, although widened in scope, is transferred to the air-column of the pipes The difference of effects produced by the two orders constitute. that variety of quality which distinguishes string-tone from horntone, and a further modification chiefly in relative times of sequence asserts its peculiarity as reed-tone; yet, again, there are in both series departures from truth of pitch, in some qualities an over-flatness of one or more harmonics, and in some an oversharpness. The blast of the trumpet combines both flat and sharp harmonics strongly. The direct order of harmonics may be likened to an ascending arpeggio coalescing into a chord-the transitive to a descending arpeggio, in some instances having intervals regulariy defined, in others starting abruptly and with wayward intensity, and in other displays passing swiftly onward to the fulness of tone, imperceptibly blended as is the "portamento " glide of voice or string.

In all the "Geigens" and "Gambas" and similar organ-pipes mimaphonic of "stringy quality," the transitive harmonics are the true cause of their speciality. Numerous experiments prove this to the eye as well as to the ear. I shall be able to show that the "Gambas" are characterised also by an over-sharpness of these transitive harmonics, and this paper is a necessary introduction to my proposed examination of the mode in which the peculiar quality of tone is built up in this attractive class of pipes.

HERMANN SMITH

\section{Can Land-Crabs Live under Water?}

PERMIT me to inform Mr. J. C. Galton that the authority for my statement in the "Outlines of Physiology" is also derived from "some book or other ;" and that this "turns out" to be the classical "Hist. Nat. des Crustacés" of Milne-Edwards, vol. ii. pp. 16, 18, with which perhaps your correspondent is unacquainted.

Milne-Edwards, in his turn, refers (p. 19) to those who have studied the land-crabs in the Antilles and on the South American coast, viz, Rochefort, Feuillée, Labat, and Brown. He elsewhere, also, treats the subject as a comparative anatomist and physiologist (Ann. des S'ciences Nat. ; Todd's "Cyclopæedia").

Whether the land-crabs of the east differ in their habits from those of the west is of course open to inquiry ; and also in what ways (either anatomically or physiologically) they differ; but the question is clearly not whether they can survive for a few hours under water, but whether practically they can live in that element or are at last asphyxiated in it.

xo, Savile Ruw, Oct. 6 John Marshall

\section{Bright Meteor's}

AT 8.55 this evening a party of six observed a meteor in the constellation Aries, or below it, which emitted light suffrcient to cast a bright gleam on the neighbouring trees. The body of the meteor shot rapidly along a course exiending about $20^{\circ}$. It then seemed to explode suddenly, and its track was luminous for a short time. The granular débris of the meteor continued to pursue ${ }_{n}$ with very much retarded velocity a path slightly deflected trom its former course : it continued to do so for several degrees" and it was, I think, fully a minute after the explosion that several of us almost simultaneously exclaimed, "It is falling." It resembled the expiring iight of one globe of a rocket charged 